\title{
Educational goals and the PISA assessments: introduction to symposium
}

Pádraig Hogan*

Education Department, National University of Ireland Maynooth, Maynooth, Ireland

At the European Conference on Educational Research in Budapest in September 2015, a joint symposium was hosted by two of the research networks of the European Educational Research Association (EERA): Network 9 'Assessment, Evaluation, Testing and Measurement' and Network 13 'Philosophy of Education'. The three papers that follow this Introduction contain the Network 13 contributions to the Symposium, amended and expanded in the light of comments received during the Budapest conference. These contributions are by scholars whose research has been to the forefront in probing ethical and conceptual issues involved in the assessment of students' achievements. The first paper is by Gert Biesta, Brunel University London and Artez, Institute of the Arts, Netherlands. The second is a joint paper by Andrew O'Shea and Francesca Lorenzi, Dublin City University. The third paper is by Andrew Davis, University of Durham, United Kingdom. A response from Network 9 was contributed by Eugenio Gonzalez, Director of the IEA-ETS Research Institute. This Introduction will outline the background to the symposium, illustrating the main reasons for hosting it as a joint initiative and identifying some of the key educational questions raised by the PISA assessments.

The symposium sought to explore the tensions and the possibilities that arise in efforts to capture advances in achieving educational goals through psychometric measurement instruments. The most familiar programme using such instruments is Programme for International Student Assessment (PISA), organised by the OECD and administered at three-year intervals. Other well-known examples include the two following programmes developed by the International Association for the Evaluation of Educational Achievement (IEA): Trends in Mathematics and Science Study and PIRLS (Progress in Reading Literacy Study). Because of its international prominence, and of recurring concerns about its consequences raised by educational researchers internationally - most recently in 2014 - PISA was chosen as the focus for the symposium.

In the 15 years since its first assessments in 2000, PISA has grown to be a high-profile international competition involving 65 'countries and economies'. In his Foreword to the report, presenting the results for the 2012 PISA assessments (OECD, 2013, 2) the Secretary-General of OECD, Mr Angel Gurría, describes the central preoccupation of educational policy-makers as:

equipping young people with the skills to achieve their full potential, participate in an increasingly interconnected global economy, and ultimately convert better jobs into better lives.

*Email: Padraig.Hogan@nuim.ie 
To this he adds:

Over the past decade, the OECD PISA, has become the world's premier yardstick for evaluating the quality, equity and efficiency of school systems in providing young people with these skills.

This predominance makes it difficult for educational policymakers at national level to ignore PISA, even if they wanted to. If their country's educational system isn't included in PISA the country is likely to be seen in a poor light where education is concerned; a non-league club as it were.

Among educational researchers there are divided views on PISA. On the one hand, the PISA assessment strategies are themselves the outcome of ongoing research on assessment. For instance, the continually expanding PISA range now includes assessment measures for Creative Problem Solving. On the other hand, there are misgivings among many educational researchers about what is seen as an inherent bias in the PISA instruments - in favour of those educational goals that can be readily quantified and indexed. A recent and intense controversy arose in May 2014 when over 80 academics from different countries (Meyer, Zahedi, et al. 2014) wrote an Open Letter to the Director of PISA expressing concerns about restrictive effects of PISA on educational practices and policies internationally. The OECD responded with a point-by-point refutation of the arguments made in the Open Letter (OECD 2014).

The exchange between the writers of the Open Letter and the OECD makes disappointing reading for anyone with high expectations of research-informed educational policy. The contents of the exchange make it difficult for the reader to avoid the conclusion that what has taken place here is more a dialogue of the deaf than a critical debate that sheds much-needed light on the central issues at stake. A few representative extracts from the exchange - I have selected three - should illustrate this.

The first extract concerns an alleged restriction of educational policy goals to 'shortterm fixes'. The Open Letter claims that 'PISA ... has caused a shift of attention to short-term fixes designed to help a country quickly climb the rankings, despite research showing that enduring changes in education practice take decades, not a few years to come to fruition'. The response from the OECD declares:

There is nothing that suggests that PISA, or other educational comparisons, have caused a 'shift to short-term fixes' in education policy. On the contrary, by opening up perspectives to a wider range of policy options that arise from international comparisons, PISA has provided many opportunities for more strategic policy design.

Elements of both claims are correct, and can be supported by empirical evidence. The Open Letter is largely correct in saying that fruitful educational change usually takes decades rather than years. A telling example is a report published in 2005 by the World Bank on four decades of educational policy development in Finland (Aho, Pitkanen, and Sahlberg, 2006). The OECD response is correct in saying that involvement of policy-makers with the OECD has regularly provided national governments with more policy options than would have been available within their own countries. A notable feature of the exchange however is the apparent reluctance on the Open Letter's part to acknowledge positive developments associated with PISA. More emphatic is the riposte from the OECD that there is nothing to suggest that PISA has caused any shift to shortterm fixes. In fact, this latter is an unconvincing claim. The heightened anxiety among 
policy-makers in many countries in the run-up to and aftermath of the release of PISA results is widely reported in the news media. Given this level of anxiety, and that there are 65 competing jurisdictions, it would be surprising if there weren't many short-term fixes among proposed remedies for a decline in performance. PISA results are announced more than a year after the round of tests takes place. This gives less than a two-year period to show raised performance levels before students sit the next round of PISA tests.

The second extract concerns the range of achievements measured by PISA. On this point the Open Letter charges that 'by emphasizing a narrow range of measurable aspects of education, PISA takes attention away from the less measurable or immeasurable educational objectives'. The OECD response states: 'PISA assesses an unprecedented range of learning outcomes and their contexts, including student performance measures, measures of social and emotional dimensions, student attitudes and motivations, equity issues, and parental support'. Here again, there isn't an acknowledgment in the Open Letter of PISA's continuing efforts to include a wider range of educational achievements within its instruments. But neither is there any recognition on the part of the OECD that there may be some central benefits of education that, of their very nature, lie beyond the reach of the most sophisticated test instruments. Examples here would be the enrichments of self-understanding and the enhancements in students' sense of personal identity that spring from resonant experiences of learning; for instance, being enabled to discover and cultivate something of the historian in oneself, or of the scientist, or of an aptitude for design and making, or of a literary sensibility.

The third extract concerns the alleged harmfulness of PISA testing. Here the Open Letter claims: 'PISA, with its continuous cycle of global testing, harms our children and impoverishes our classrooms, as it inevitably involves more and longer batteries of multiple-choice testing'. The OECD response is that

PISA is only administered to a small fraction of students and ... only around a third of the PISA items are in multiple-choice format. Moreover, the length of the PISA tests has not increased since the first survey in $2000 \ldots$ The claim that a two-hour test could 'endanger the well-being' of students and teachers is thus unfounded.

This rebuttal by the OECD correctly identifies an incomplete understanding of the PISA procedures on the part of the signatories of the Open Letter. But here and elsewhere in its contents, the OECD response neglects to acknowledge that there is widespread apprehension in many countries about the enduring consequences for educational practice of the PISA assessment cycles. These cycles are indeed periodic rather than continuous, but their high-stakes nature means that their influence on educational policy and practice is not only continuous, but also decisive.

There are many further examples in the Open Letter and the PISA response of an exchange that is largely at cross purposes. Such differences have a history. Criticisms of the PISA assessments by educational researchers over the last decade characteristically questioned the design of the PISA models, regularly focusing on complex technical and statistical matters (Goldstein, 2004; Sjøberg, 2007; Jerrim, 2011; Kreiner and Christensen 2014). In response to such criticisms it is unsurprising that the OECD has developed a robust capacity to defend its procedures and its rationales, though this defence tends to appear in publications like the TES Magazine than in research articles (e.g. Schleicher, 2013). What is less in evidence is an openness on the part of the OECD to engage with critiques coming from educational researchers outside of its own 
research circles and from leaders among practitioners in schools. Both were represented among the signatories the Open Letter. Of course, this letter contained little that acknowledged merits in PISA. But it also contained a number of constructive suggestions on which the OECD response remained silent. This $i$ surprising, given the commitment to ongoing research and development that informs the expansion of the PISA tests into areas other than cognitive achievement.

A disquieting feature of the OECD response is its attribution of an ideological stance' to the Open Letter. On first reading this I was taken aback, but concluded that it may have been an impromptu, or unguarded comment. A few months after the publication of the OECD response the Director of PISA was interviewed by The Irish Times newspaper during a visit to Dublin (18 November 2014) about the Open Letter and the OECD response. The interviewer quoted the following sentence from the Open Letter: 'No reform of any consequence should be based on a single narrow measure of quality' and asked the Director if he agreed with that statement. In reply the Director remarked: 'I don't know of any reform that is based on any single metric. But too many reforms are based on single ideas, ideologies pet projects and vested interests, including those of academics, without any empirical metric or evidence base'.

This reported remark recalled to my mind the earlier attribution by the OECD of an ideological stance to the signatories of the Open Letter. It prompted me to read both documents again. During this second and subsequent readings, the idea of a joint symposium by two networks of EERA was born and took shape. In view of an emergent non-dialogue between one of the world's most influential bodies in educational policy and an international group of educational researchers, some new departure was called for. It seemed appropriate, and indeed necessary, to avail of the resources of a body like the EERA to provide a forum where the crucial issues at stake could be pursued in an investigative, open-ended way. It is of course difficult for any research in education to be entirely free of ideological influences. All the more important then that educational research should be critical of its own assumptions and guided insofar as possible by a stance that is primarily exploratory; a stance moreover that is inclusive of a range of research perspectives. These were the expectations that were shared with the contributors to the joint symposium in Budapest and with the representatives of both networks involved in its planning and execution.

Key questions to be addressed by the symposium included:

(1) To what extent is it possible to tailor and adapt PISA-type instruments to capture the deeper and more inclusive and goals of education?

(2) Are there some goals of education that are, by their nature, beyond measure? If so, does that mean they are beyond appraisal?

(3) To what extent can qualitative forms of assessment play a meaningful role in the review and development of national educational policies?

(4) Can a reliance on instruments such as PISA serve to recast the question of quality in education as a question of indexed quantity (e.g. of scores and grades)?

It was acknowledged that a 90-minute symposium was unlikely to do full justice to such far-reaching questions, but it was felt that some important inroads on them might yet be made. It was also felt that if a project like this was worth pursuing, it might profitably develop over further conferences into a larger and longer undertaking than imagined at the outset. A bountiful harvest is the fruit of careful effort, renewed co-operation and judicious patience. 


\section{Disclosure statement}

No potential conflict of interest was reported by the author.

\section{References}

Aho, E., K. Pitkanen, and P. Sahlberg. 2006. Policy Development and Reform Principles of Basic and Secondary Education in Finland since 1968. Education Working Paper Series; No. 2. Washington, DC: World Bank.

Goldstein, H. 2004. "International Comparisons of Student Attainment: Some Issues Arising from the PISA Study." Assessment in Education, 11 (3): 319-330.

Jerrim, J. 2011. England's "Plummeting" PISA Test Scores between 2000 and 2009: Is the Performance of Our Secondary School Pupils Really in Relative Decline? DoQSS Working Paper No. 11-09. Institute of Education, University of London.

Kreiner, S., and Christensen, K. B. 2014. "Analyses of Model Fit and Robustness: A New Look at the PISA Scaling Model Underlying Ranking of Countries according to Reading Literacy." Psychometrika 79 (2): 210-231.

Meyer, H.-D., K. Zahedi, et al. 2014. Open Letter to Andreas Schleicher. Paris: OECD. http://bil dung-wissen.eu/fachbeitraege/basistexte/open-letter-to-andreas-schleicher-oecd-paris.html.

OECD. 2013. PISA 2012 Results in Focus: What 15-Year-Olds Know and What They Can Do with What They Know. http://www.oecd.org/pisa/keyfindings/pisa-2012-results-overview.pdf.

OECD. 2014. Response to Points Raised in Heinz-Dieter Meyer 'Open Letter'. http://www.oecd. org/pisa/aboutpisa/OECD-response-to-Heinz-Dieter-Meyer-Open-Letter.pdf.

Schleicher, A. 2013. "Attacks on PISA Are Entirely Unjustified". TES Magazine, August 2, 2013. https://www.tes.com/article.aspx?storycode $=6345213$.

Sjøberg, S. 2007. "PISA and 'Real Life Challenges': Mission Impossible?" In PISA According to PISA: Does PISA Keep What It Promises? edited by S. Hopman, 203-224. Vienna: LIT Verlag.

The Irish Times. 2014. "OECD Boss Defends PISA Tests against Criticism from Academics." The Irish Times, November 18, 2014. http://www.Irishtimes.com/search. 